\title{
Development of An Interactive Computer Based Learning Strategy To Assist in Teaching Water Quality Modelling
}

\begin{abstract}
The following paper presents a computer based learning strategy to assist in introducing and teaching water quality modelling to undergraduate civil engineering students. As part of the learning strategy, an interactive computer-based instructional (CBI) aid was specifically developed to assist students to set up, run and analyse the output from a commercially available water quality model (WQMAP) for a hypothetical raw sewage spill. The CBI aid comprised a Hypertext Markup Language (HTML) module with helpful text and still graphics, and links to on-screen recorded motion movie clips showing on-screen actions and voice narrations during the instructors absence. An anonymous class questionnaire to assess the students' perceptions of the developed approach found that most students felt they were able to complete the project with minimum supervision, and have acquired a basic understanding of water quality modelling as a result of the activity. Additionally, almost all of the students found the CBI aid helpful and easy to follow.
\end{abstract}

Keywords: simulations, interactive learning environment, teaching/learning strategy, computer-based instructional aid 


\section{Introduction}

The benefits of using water quality models as an aid in understanding and improving the environmental standards of rivers, estuaries and coastal waters have been recognised within the engineering and science industry for more than 20 years. The models can be used to find the best answers to both existing and potential environmental problems. Additionally, models have not only been helpful in obtaining the best answers to environmental pollution problems, but have also been resourceful in demonstrating solutions at meetings and public inquires. Most modelling packages now include colour graphics and animations to display model predictions, educating the most inexperienced of observers in the problem at hand.

Thus the increased use of modelling has seen employers of graduates within the water-related industry come to expect they will be equipped with the necessary computer-based skills. However, introducing and teaching water quality models to undergraduate students as part of their course curriculum has been hindered, apparently due primarily to a lack of teaching support materials (e.g. teaching manuals and study guides). However, while in most cases the provided software manuals are comprehensive, these tend to be targeted at the experienced user, and hence are too cumbersome for the lecturer to use.

Having recognised the importance of giving students this basic training, the difficulty faced by the authors in teaching water quality modelling was development of the necessary resources in terms of available materials (as mentioned above), staff and sufficient time to deliver the activity during the semester. Thus, a practical and effective instructional strategy was necessary. The authors decided to resolve this limitation by developing an interactive computer-based instructional (CBI) aid to assist students to set up, run and analyse the output from a commercially-available water quality model (WQMAP) for a hypothetical raw sewage spill. The CBI aid had the significant benefit of permitting students to work through a defined activity at a time and pace suited to them, and not restricting them to the limited times when a tutor was/could have been available. The CBI aid comprises a Hypertext Markup Language (HTML) module with links to recorded Lotus Screencam movies. Lotus Screencam is a dynamic screen capturing tool that captures (and stores as a playable movie) all screen activity, including mouse movements, plus a voice-over 
narrative recorded over a user defined timeframe (Garner, 1997). The movie therefore contains the actions performed on the computer screen, with the option of voice over narration that can be used to explain the actions and to provide additional information.

The expectations and assumptions of this study were to: (a) improve students' understanding of water quality through the use of specialised software; (b) provide undergraduate students with an introduction and basic training in water quality modelling as part of a final year core subject at a pace controlled by the students; (c) prepare students for the type of problems they may encounter in the workplace; and (d) assist staff in the management of their teaching. This paper presents a description of the activity and results of a formal class survey undertaken to gauge students' perceptions of the usefulness and effectiveness of both the activity and the CBI program.

\section{Related Research}

Brown et al., (1983) and Farhnam-Diggory (1990) found students do not learn simply by receiving information, but rather constructively through a process of reflection on material and interaction with it, which thereby creates an understanding. Thus, interactivity forms an effective learning procedure, that allows the student to become engaged and to reflect on interesting problem issues. The process behind an activity can be learned from a book, however, the necessary skills and conceptual knowledge are more difficult to acquire from written materials. Research by Aveling et al., (1992) found that interactivity in the form of lectures and tutorials is more effective in teaching such concepts than can be provided by only a book. Additionally, Neoman \& Spohrer (1996) found that an engaged student is a motivated student. However, in the standard lecture-style class, students do not always ask questions that may occur to them throughout the course of the class. This may be due to a number of factors: inability to clearly formulate or express the question; disinterest in the topic; shyness in large groups; uncertainty as to the appropriateness

of the question, etc. Additionally, the instructor may not have the luxury of encouraging many questions throughout the class due to time constraints imposed in order to cover the required volume of material (McIntyre \& Wolff, 1998). 
A method of partially supplementing classroom teaching is the provision of an interactive learning environment that pays more attention to student needs (eg Dharmappa et al, 2000; Parkinson and Hudson, 2002). Benefits include: the ability to provide rapid, compelling interaction and feedback to the student; can help motivate students by providing information in a form that is structured and perceptually easy to process; also, unlike the classroom environment, each student can learn individually at the computer at his/her own preferred time, location (lab, home, office), and pace; and many more examples can be covered than might otherwise be possible within a classroom environment (McIntyre \& Wolff, 1998).

Dick \& Carey (1996) describe an instructional strategy as being the general components of a set of instructional materials, and the procedures to be used to attain particular learning outcomes from students. When used appropriately, instruction strategies are highly effective in achieving the desired outcomes. Although no single strategy of instruction is designed to achieve all outcomes of instruction, the instructor must select a series of teaching activities based on desired outcomes, then sequence these activities in a particular order so as to accomplish a series of goals (Anderson, 1999). Appropriately planned and delivered instructional strategies assist the instructor to attain desired outcomes (Lee, 2001).

For simple and general learning, Gagne et al., (1992) suggested the instructional strategy should include nine "events of instruction": (1) gain attention; (2) inform the learner of the objective; (3) stimulate recall of prerequisite learning; (4) present stimulus materials; (5) provide learning guidance; (6) elicit performance; (7) provide feedback; (8) assess performance; and (9) enhance retention and transfer. However, learning to use computer application software involves procedural rules and psychomotor skill learning; hence, other important events need to be considered for the teaching of computer application software (Lee, 2001).

Smith \& Ragan (1992) describe procedural rules as a series of generalised steps initiated in response to reach a specified goal. Before a procedure is taught, the instructor must clarify the procedure and list the steps and decisions of the actions in a clear procedure. Landa (1983) found that computer application 
software involves procedure learning; hence, it is important that the purpose of learning a procedure be emphasised, with finished examples being presented before actual instruction. With procedure learning, the learner will be basically motivated because they can complete tasks more efficiently and reliably than with trial-and-error approaches. In most situations, the best plan seems to be simple presentation of the procedure with demonstrations of the applications of the procedure, unless the primary goal is for learners to acquire skills in generating procedures.

\section{Developing the Computer Based Learning Strategy}

While there are many different learning strategies, the following seven key steps were considered necessary to develop the water quality modelling activity:

1. Select the appropriate subject for the activity to be delivered;

2. Provide a practical and locally based hypothetical water pollutant scenario;

3. Decide on the approach of testing their understanding (ie. tests or assignments);

4. Select a user-friendly and interactive water quality model, which would simply be for students to navigate and would not require any programming (coding) experience;

5. Develop a functional and easy to use computer based instructional (CBI) aid with a variety of information for the users to access, such as text and still graphics;

6. Motion video clips with audio narration to assist students during the instructor's absence; and 7. Evaluate the developed teaching/learning strategy and CBI aid.

The following sections provide a detailed description of the methodology and how each of these points was implemented. 


\section{Application}

The water quality modelling activity was delivered during Semester II, 2002, as part of a fourth year subject "Water and Wastewater", offered within the Griffith University Bachelor of Engineering in Civil Engineering degree (Gold Coast Campus) [Step 1]. The subject was taught over a period of 13-weeks, for three hours of timetabled contact each week ( $1 \times$ hour and $1 \times 2$ hour session). The course aimed to introduce civil engineering students to important concepts relating to water and wastewater (Lemckert, 1999). Therefore, the computer-based water quality modelling activity was introduced and expected to complement the theory-based component.

The water quality modelling activity was delivered to all students during Week 7, the two hour lecture timeslot being used to introduce the basic concepts and principles of water quality modelling; a brief overview of the actual water quality software; how to use the teaching aids; and expected outcomes as part of the activity requirements. As part of the activity assessment, students were required to submit a written assignment on completion of the activity. The learning outcomes expressed for the activity were practical: (1) set up and run a commercial water quality model (WQMAP) for a hypothetical sewer overflow with minimal supervision, and at a pace students could control; (2) interpret and report the model results as a professional report. It is also important to note that the developer was also the instructor for the activity, and is experienced in utilising and teaching water quality modelling on a commercial level.

The instructional strategy and the water quality model were installed on 12 desktop computers within the computing lab. Due to the number of computers available compared with students (29), the students were given the option of working with a partner. For the following three weeks $(8-10)$ only $1 \mathrm{x}$ one-hour computing sessions were scheduled with an instructor, instead of the 2-hour timetabled slot. For the next three weeks (weeks 11 - 13) of the semester the students continued working through the activity unsupervised, and were able to work on the activity at their leisure. 
After careful consideration, it was decided that a control group was niether necessary nor appropriate, and that the entire class would be provided with the same activity and, consequently, resources. This was due to, the authors' aim of ensuring educational equity for the entire class. While this was recognised as being less than ideal, it is important to note that such an approach has been used in numerous studies undertaken by other researchers (e.g Champmand and Martin, 1995; Dharmappe, et al., 2002; Colwell et al., 2002) to maintain equity, and that the major aim here was to assess the students' perception of the effectiveness of the developed teaching/learning approach.

\section{Hypothetical Scenario}

As part of the planned instructional strategy, students were presented with a project that required them to model and report on a hypothetical overflow of untreated wastewater from a nearby pump station into the Nerang River estuary, Gold Coast, Queensland, Australia, following a major rainfall event [Step 2]. Although the scenario itself was hypothetical, it was considered a useful and realistic application.

The project brief contained all necessary information for students to complete the activity, including: (a) time and date of the spill; (b) location of the spill; (c) volume of untreated sewage; \&(d) the e-coli counts on day-1 and day-3 of the spill.

Initially, students were required to run the hydrodynamic numerical model using the hydrodynamic grid provided, and to generate currents for the entire estuary over the prescribed five-day period. Specifically, this task required students to set up and create a new simulation, using the relevant data provided as inputs; ie. linking of wind, ocean forcing and river discharge to drive the model and adding time series points within certain parts of the estuary to observe and compare water elevations and speed along the estuary graphically. Once the current file had been created, students used the current file as input into the pollutant transport model to predict the distance and decay of e-coli counts within the receiving waters. This task required students to specify the location of the overflow; set up the pollutant transport run card with 
necessary parameters; to time series points to view the e-coli counts graphically; and modify the colour keys to reflect predicted e-coli counts.

On completion of the hands-on modelling component, students were expected to develop a professional and detailed report using the various output options from each of the models, in the form of figures and graphs [Step 3]. Additionally, they were required to explain model predictions and provide an estimate of the anticipated length of time before the receiving waters would be safe for primary (swimming, fishing) and secondary (boating) contact, based on Australian \& New Zealand Environment \& Conservation Committee (ANZECC 2002) water quality guidelines. This was seen by the authors as a useful method of assessing their performance and enhancing their understanding of the activity, including their knowledge of environmental issues that extend beyond that of simply running a model.

\section{Water Quality Model}

The water quality model chosen for this educational activity was a commercially available software package called WQMAP (Water Quality Mapping Analysis Package [http://www.wqmap.com, Siteed - 19 May 2005]), developed by Applied Science Associates, Inc. This model uses information technology to combine hydrodynamic and pollutant transport models with GIS (Geographical Information System) and data management tools (Howlett et al, 1996). WQMAP combines each of the modelling components and mapping capabilities through an intuitive graphical user interface that runs under Microsoft Windows ${ }^{\mathrm{TM}}$. Also, WQMAP's drop down menus allowed students to set up, run and play simulations without any programming experience or formal training [Step 4]. Figure 1 shows a snapshot of the WQMAP interface and the predicted water movement through the Nerang River system, Gold Coast, Australia. Furthermore, WQMAP had recently been incorporated as part of the Gold Coast City Council's (GCCC) decision support system as a management tool for future land use consideration for the Nerang River region, for planning and monitoring the health of the estuary and its tributaries. Hence, providing hands-on learning to 
WQMAP would give an advantage to any graduates seeking employment with the GCCC catchment management group.

WQMAP includes a detailed manual and example applications for an estuary in the United States. It was the authors' belief that the manual was too advanced, too difficult for an inexperienced user to follow and too taxing on both students' and instructors' time to deliver and complete the activity. To this end, the authors specifically developed a basic interactive CBI aid.

\section{Computer Based Instructional Aid}

As mentioned in the introduction, the base of the interactive water quality modelling CBI aid, was a series of interlinked instructional HTML pages designed to assist the student to set up and run WQMAP and to analyse the output data. Importantly, this HTML operation/coaching manual permitted the student to work through the required activity without the presence of a demonstrator, thus they could complete the activity at their own time and pace. The main factors for the authors' choice of the HTML pages were: (a) it was user-friendly and students would be familiar with using the various features provided to navigate; (b) the time taken to develop the CBI aid was far less expensive than more sophisticated software; (c) its ability to run on varying computing capacity; and (d) it takes up minimal disk storage space.

The CBI aid consisted of a set of 43 HTML pages, with each page containing links or buttons to direct the student to the next, previous or home page. The pages were progressively ordered to restrict students from skipping relevant pages and steps, thus missing important and useful information. Figure 2 shows the opening HTML page to the pollutant transport model.

Once the CBI program was initiated, the first HTML page appears - this welcomes the students and explains how to use the CBI aid. Students are then able to work through the module by clicking on the links 
located on each of the HTML pages, describing the hypothetical spill event; objectives of the assigned activity; a description of the water quality model; and a step-by-step guide to setting up and running the hydrodynamic and pollutant transport models. Each page contains text and still graphics of drop-down menus, completed run cards and expected model outputs [Step 5]. The level of information has been intentionally kept to a minimum and a relatively basic level, as the activity was intended only as an introduction to water quality modelling and its potential uses and benefits, and not as a complete training manual. Student were also able to move forwards or backwards through the pages at any time. The hydrodynamic and pollutant transport modelling components have been broken up into simple step-by-step instructional pages aimed at supplying students with sufficient information on certain necessary features and inputs for completion of prescribed tasks.

As previously mentioned in the development phase, the authors were particularly interested in creating motion video clips with audio narration that would be integrated into the CBI (thorugh links on the appropriate HTML pages) to assist students to undertake various steps of the modelling process without the presence of an instructor. These movies are recordings of computer screen responses (projections) to the movement and clicking of a mouse or the typing of keys on the keyboard. That is, the movies represent the visual output of the computer responses to the operator's actions. The sound is that of the operator saying what they did to cause that action. To generate these movies the authors used software called Lotus ScreenCam (Garner, 1997). While working through the CBI, the students would benefit by being able to view all mouse pointer movements and on-screen actions, as well as listening to the audio narrations as demonstrated by the instructor when required to perform a particular modelling task. The pre-recorded movie clips were strategically linked to particular HTML pages, and by clicking on the ScreenCam icon, students could watch and listen to the clips step-by-step and at any time stop, play, rewind or pause the clip [Step 6]. By pausing the clip, students were able toggle to the model and immediately apply the directions conveyed, which was also seen as a method of creating a pleasant environment for students who weren't highly computer literate. Figure 3 shows a snapshot of the ScreenCam movie clip for setting up the hydrodynamic run card; note the ScreenCam play-back icons and status are shown in the bottom right corner. 


\section{Results and Discussion}

Towards the end of the activity, twenty-one students completed an anonymous survey (questionnaire) designed to source data on student perceptions of the CBI-based teaching/learning strategy. The questionnaire comprised two components; the first focused on the specific aspects of the general issues and the trainers'/students' overall perceived effectiveness; while the second part focused on the CBI aid. The questionnaire was based on a five-point scale ranging from 'strongly agree' to 'strongly disagree'. For summary purposes, the five point rating scale was reduced to a three-point scale combining 'strongly agree' with 'agree', and 'strongly disagree' with 'disagree'. Anonymity was guaranteed. Table 1 shows the results of student responses towards general issues and the trainers'/students' overall effectiveness. Table 2 shows the results of student responses towards specific aspects of the CBI aid.

The majority of respondents (16 of 21 or $76 \%$ ) felt they have a basic understanding of water quality modelling, which was very encouraging, particularly as this was one of the main aims of the activity. Furthermore, $61.9 \%$ agreed that sufficient time with the instructor had been provided, with the same percentage agreeing they were able to complete the project with minimum supervision; while $76.2 \%$ and $71.4 \%$ agreed or strongly agreed that project objectives and deliverables were clear, respectively. Ninetyfive percent of respondents (20 of 21) agreed or strongly agreed that having an instructor present was helpful. Finally, a mixed response was received as to whether the trainer was more useful than the HTML package, with $52 \%$ agreeing, $10 \%$ disagreeing and $38 \%$ of respondents remaining neutral. The varied responses to this question were very interesting, particularly since $38 \%$ remained neutral. This would suggest that if a trainer was less experienced and less enthusiastic, the majority of students may have responded that the HTML package is more useful than the trainer.

With regard to the CBI aid, most students (19 of 21, or 90\%) perceived the content was sufficiently basic for them to follow without becoming confused or overwhelmed. Ninety-five percent of students agreed the 
HTML module was helpful and easy to follow (navigate through). With regard to the pre-recorded movie clips, 95\% agreed these were helpful, and 90\% agreed the on-screen demonstrations made the project easier. However, when asked if the voice narration was more useful than the on-screen demonstrations, 86\% (18 of 21) agreed. This was an interesting result, as this reaction had also been observed in class. During the first two (2) weeks of the subject certain computers did not have sound cards installed, which meant certain groups of student were only able to see the demonstrator's mouse-pointer movements without listening to the instructions. This in turn had a noticeable effect on students' progress; they progressed at a slower rate and became much more frustrated, particularly since they were less confident in mimicking the same on screen actions. This was really not surprising, as the CBI aid had been designed to have sound included. Finally, all (21 of 21, or 100\%) students agreed the ScreenCam on-screen demonstrations and voice narrations made the water quality model simple to set up and run.

As part of the questionnaire, space was provided for students to describe ways in which the activity can be improved in order to enhance the educational quality. Most suggestions concerned increases and upgrades to the disk space on the computers to save the model output, and increasing the access and availability of the room. One student also suggested the trainer be given a separate screen to run through the program. The latter suggestion is being considered by the authors for inclusion in future CBI developments.

\section{Conclusion}

This paper looked at using a newly proposed seven step structured approach to provide an introduction and basic training in water quality modelling for undergraduate engineering students. An interactive CBI aid was specifically developed to assist students to set up, run and analyse the output from a water quality model,. The CBI aid comprised a multi-paged HTML module with links to recorded Lotus Screen cam movie clips. These clips, with narration, helped lead students through various aspects of the water quality model. Significantly, the CBI was designed to be used without a demonstrator being present, thus permitting the student to complete an assigned task at a rate suitable to themself. 
The computer-based learning strategy was evaluated using an anonymous questionnaire to assess the students‘ perception of the developed approach and was found to be successful in providing hands-on training in small, easy steps. The project success was primarily due to the trainer, set up of the HTML module and the ScreenCam movie clips showing on-screen actions and the instructor's voice narrations. Future implementation of such CBI will need to take into account the importance of a well-trained and motivated demonstrator, and suitable resources.

\section{Acknowledgments}

The authors would like to gratefully acknowledge Applied Science Associates Inc. for permission to use WQMAP as a teaching aid and Griffith University Gold Coast Campus, for the opportunity and their support. The authors would also like to thank the students completing the survey form and Dr Brian King for his support.

\section{References}

Anderson, T. P. (1999). Using models of instruction. In C. R. Dills, \& A. J. Romiszowski, Instructional development paradigms (pp. 521-533). Englewood Cliffs: Eductional Technology Publications.

ANZECC, (2000). Australian and New Zealand water quality guidelines for fresh and marine waters. A publication by the Australian and New Zealand Environment and Conservation Council (ANZECC) and Agriculture and Resource Management Council of Australia and New Zealand (ARMCANZ)

ASA Inc. (2005). Water Quality Mapping and Analysis Package. http//www.wqmap.com. Sited $-19^{\text {th }}$ May 2005.

Aveling, N., Smith, S., \& Wilson, C. (1992). Meeting the needs of isolated students: is a technological fix the answer? Parer, Ed. Academia Under Pressure: Theory and Practice for the $21^{\text {st }}$ Century, Research and Development in Higher Education, 15, Churchill Vic: HERDSA. 
Brown, A. L., Bransford, J. D., Ferrara, R. A., \& Campione, J. C. (1983). Learning, remembering and understanding. Handbook of Child Psychology: Cognitive Development, Vol. 3, Wiley, pp. 77 -166.

Chapman, G. M. and Martin, J.F. (1995). Computerised business games in engineering education,. Computers and Education, Vol 25, pp 67-73.

Colwell, C., Scalon, E and Cooper, M. (2002). Using remote laboratories to extend access to science and technology. Computers and Education, Vol 38, pp 65 - 76.

Dick, W., \& Carey, L. M. (1996). The systematic design of instruction. New York: Addison-Wesly Pub.

Dharamappa, H. B., Corderoy, R. M. and Hagare, P. (2000). Developing an interactive multimedia software package to enhance understanding of and learning outcomes in water treatment processes, Journal of Cleaner Production, 8, 407-411

Farnham-Diggory, S. (1990). Schooling. The Developing Child. Harvard University Press. MA, Cambridge.

Gagne, R. M., Briggs, L. J. \& Wager, W. W. (1992). Principles of instructional design. New Jersey: Wadsworth Publishing.

Garner, S (1997). Cost effective multimedia production for frequently updated courseware. Proceedings of The Australian Society for Computers in Learning in Tertiary Education Conference 1997. Curtin University, Australia, $7 \quad-\quad 10 \quad$ December $1997 \quad$ (sited 7/10/2005 http://www.ascilite.org.au/conferences/perth97/papers/Garner/Garner.html). 
Howlett, E., Mendelsohn, D., Swanson, C., and M.Spaulding. (1996) An integrated water quality and oil spill model system. Proceedings of the North American Water and Environment Congress 1996, sponsored by ASCE, Anaheim, CA, 22-28 June 1996.

Landa, L. N. (1983). The algo-heuristic theory of instruction. Englewood Cliffs, NJ: Educational Technology Publications.

Lee, S. (2001) Development of instructional strategy of computer application software for group instruction. Computers \& Education 37, pp 1-9.

Lemckert, C. (1999) Improving the delivery of problem/project-based learning in a traditional teaching environment. Proc $2^{\text {nd }}$ Asia - Pacific Forum on Engineering and Technology Education, Sydney, 149 152.

McIntyre, D. R., and Wolff, F., (1998). An experiment with WWW interactive learning in university education. Computers and Education 31, 255-264.

Neorman, D. A., \& Spohrer, J.C. (1996). Learner-centered education. Communications of the ACM, 39(4).

Parkinson, B. and Judson, P. (2002). Extending the learning experience using the Web and a knowledge based virtual environment, Computers and Education, 38, 95-102.

Smith, P., \& Ragan, T. (1992). Instructional Design. Upper Saddle River, NJ: Prentice Hall. 


\section{Figure Captions}

Figure 1: Snapshot of the WQMAP (water quality model) interface showing the predicted water movement through the Nerang River system, Gold Coast, Australia.

Figure 2: The opening HTML page describing the pollutant transport model.

Figure 3. Screencam movie clip demonstrating how to create a hydrodynamic scenario, with the play-back icons and status shown in the bottom right corner. 


\section{Figures}

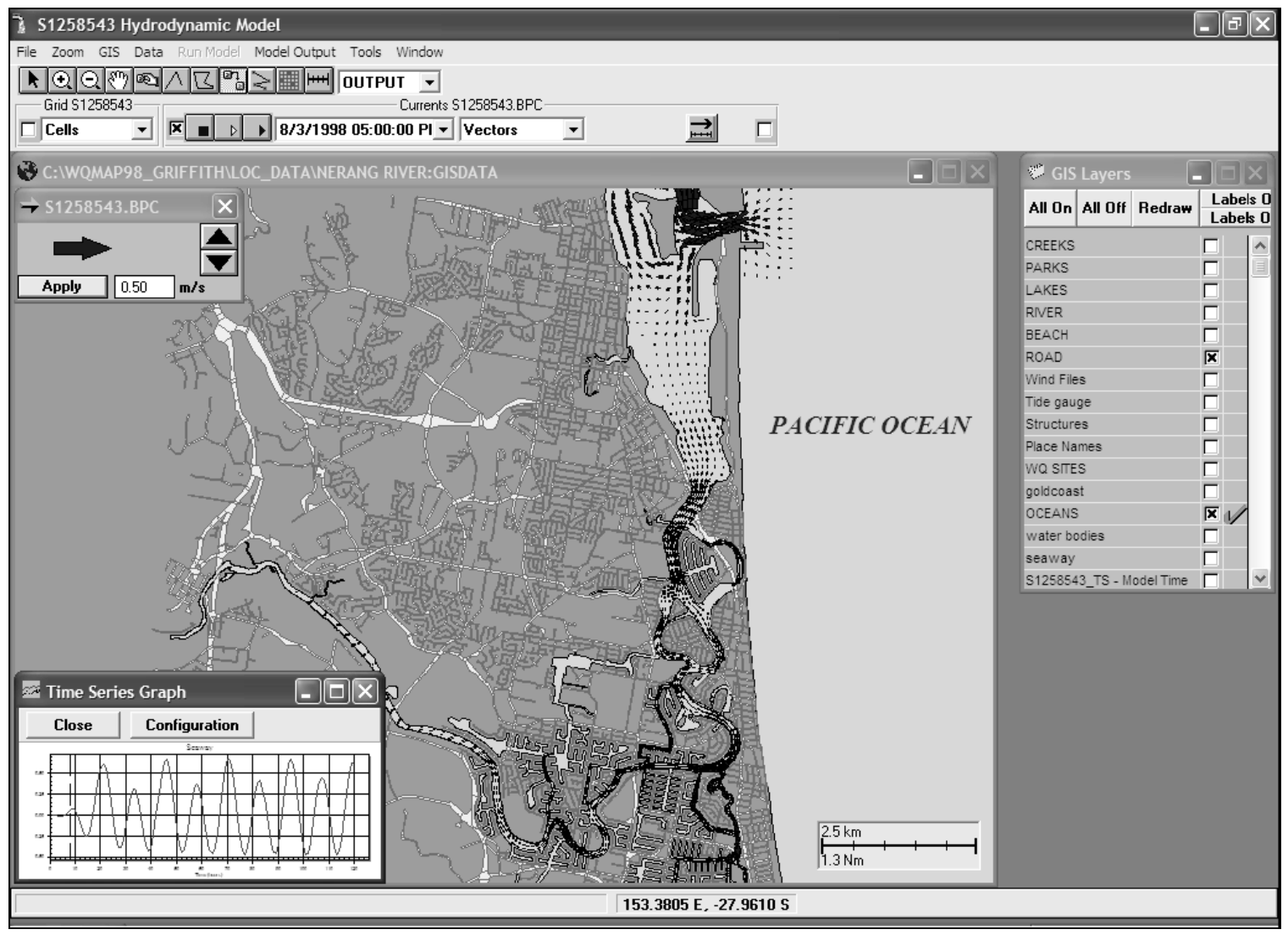

Figure 1.

\section{CLICK HERE TO START}

Return to hydrodynamic modelling

BFMASS: Boundary Fitted Pollutant Transport Model

The pollutant transport model system solves the conservation of mass equation on the boundary fitted grid to predict time varying fields of constituent concentration. Single and multiple, constant and tim suspended sediment, nutrients, organies and conservatve tracers The standerd model is conf run in a vertically a araed mode but can optionally run in the dimensions. The constituent fotes model consists of two possible configurations for singlo independent and multiple, linked or independent constituents incorporating increasingly complex reaction kinetics:

\section{TABLE OF CONTENTS}

- Create Now Mass Transport Scenario

Add Time Series Locations

View Model Time Series Outout

View Concentration Field Output

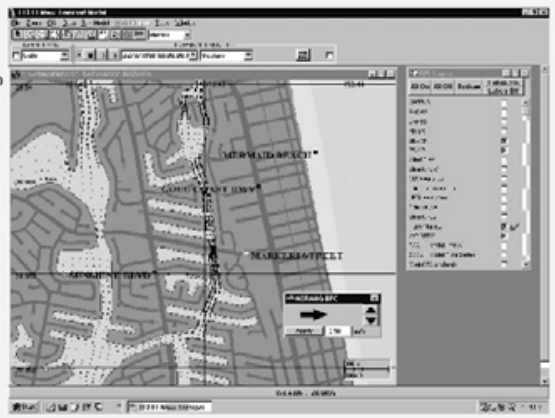

Figure 2. 


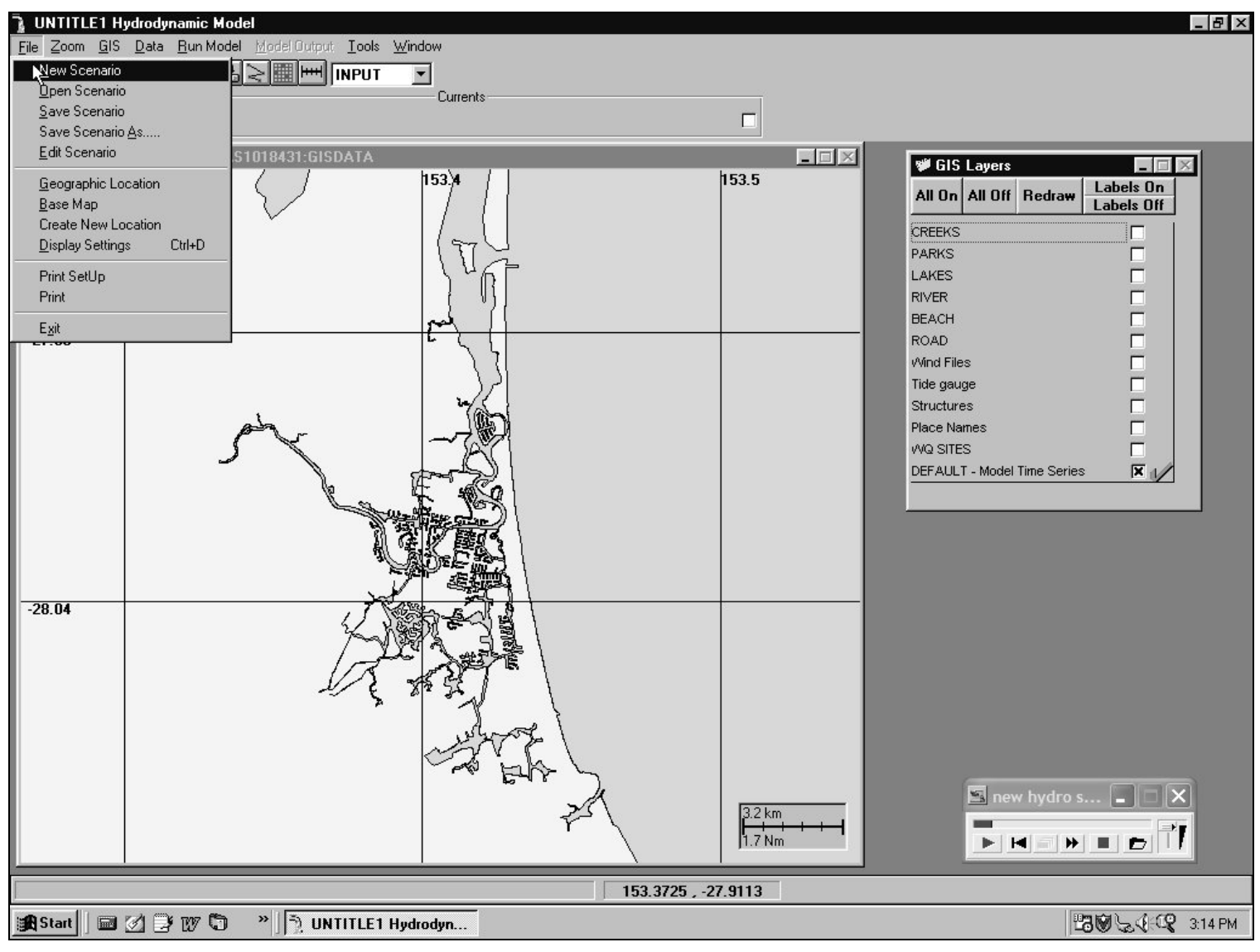

Figure 3. 


\section{Table Captions}

Table 1: Results of the student responses towards general issues and the trainers/students overall effectiveness (response; \% (n))

Table 2: Results of the student responses towards specific aspects of the teaching module (response; \% (n)) 


\section{Tables}

Table 1.

\begin{tabular}{llcc}
\hline Questions & Agree & Neutral & Disagree \\
\hline (1). The objectives of the project were clear & $76(16)$ & $24(5)$ & $0(0)$ \\
$\begin{array}{l}\text { (2). The project deliverable's were clear } \\
\text { (3). It was helpful having a instructor present }\end{array}$ & $71(15)$ & $24(5)$ & $5(1)$ \\
(4). There was enough time with the trainer & $65(20)$ & $5(1)$ & $0(0)$ \\
(5). I was able to complete the project with minimal & & $33(7)$ & $5(1)$ \\
supervision & $62(13)$ & $33(7)$ & $5(1)$ \\
(6). I have a basic understanding of water quality modelling & $76(16)$ & $24(5)$ & $0(0)$ \\
(7). The trainer was more useful than the html package & $52(11)$ & $38(8)$ & $10(2)$ \\
\hline
\end{tabular}

Table 2.

\begin{tabular}{|c|c|c|c|}
\hline Questions & Agree & Neutral & Disagree \\
\hline (1). The html module was helpful & $95(20)$ & $5(1)$ & $0(0)$ \\
\hline (2). The html module was easy to follow & $95(20)$ & $5(1)$ & $0(0)$ \\
\hline \multicolumn{4}{|l|}{ (3). The content was basic enough for me to follow without } \\
\hline getting to confused & $90(19)$ & $10(2)$ & $0(0)$ \\
\hline (4). The screen cam recordings were helpful & $95(20)$ & $5(1)$ & $0(0)$ \\
\hline (5). The on screen demonstrations made the project easier & $90(19)$ & $10(2)$ & $0(0)$ \\
\hline \multicolumn{4}{|l|}{ (6). The voice narration was more useful than the on-screen } \\
\hline demonstration & $84(18)$ & $10(2)$ & $5(1)$ \\
\hline \multicolumn{4}{|l|}{ (7). The combination of the on-screen demonstrations and } \\
\hline voice narrations made it simple to follow & $100(21)$ & $0(0)$ & $0(0)$ \\
\hline
\end{tabular}

